\title{
BMJ Open Application of the Safety Attitudes Questionnaire (SAQ) in Albanian hospitals: a cross-sectional study
}

\author{
Adriatik Gabrani, ${ }^{1}$ Adrian Hoxha, ${ }^{2}$ Artan Simaku, ${ }^{3}$ Jonila (Cyco) Gabrani ${ }^{1}$
}

To cite: Gabrani A, Hoxha A, Simaku A, et al. Application of the Safety Attitudes Questionnaire (SAQ) in Albanian hospitals: a crosssectional study. BMJ Open 2015;5:e006528.

doi:10.1136/bmjopen-2014006528

- Prepublication history for this paper is available online To view these files please visit the journal online (http://dx.doi.org/10.1136/ bmjopen-2014-006528).

Received 5 September 2014 Revised 6 February 2015 Accepted 2 March 2015

CrossMark

\begin{abstract}
${ }^{1}$ Department of Health Management, Faculty of Public Health, University of Medicine, Tirana, Albania ${ }^{2}$ Department of Health and Environment, Faculty of Public Health, University of Medicine, Tirana, Albania ${ }^{3}$ Institute of Public Health, Tirana, Albania
\end{abstract}

Correspondence to Jonila (Cyco) Gabrani; jonila11@yahoo.com

\section{ABSTRACT}

Objective: To establish the reliability and validity of the translated version of the Safety Attitudes Questionnaire (SAQ) by evaluating its psychometric properties and to determine possible differences among nurses and physicians regarding safety attitudes.

Design: A cross-sectional study utilising the Albanian version of the $S A Q$ and a demographic questionnaire.

Setting: Four regional hospitals in Albania.

Participants: 341 healthcare providers, including 132 nurses and 209 doctors.

Main outcome measure(s): The translation, construct validity and internal validity of the $S A Q$. The SAQ includes six scales and 30 items.

Results: A total of 341 valid questionnaires were returned, for a response rate of $70 \%$. The confirmatory factor analysis and its goodness-of-fit indices (standardised root mean square residual 0.075 , root mean square error of approximation 0.044 and comparative fit index 0.97) showed good model fit. The Cronbach's $\alpha$ values for each of the scales of the $\mathrm{SAQ}$ ranged from 0.64 to 0.82 . The percentage of hospital healthcare workers who had a positive attitude was $60.3 \%$ for the teamwork climate, $57.2 \%$ for the safety climate, $58.4 \%$ for job satisfaction, $37.4 \%$ for stress recognition, $59.3 \%$ for the perception of management and $49.5 \%$ for working conditions. Intercorrelations showed that the subscales had moderate-to-high correlations with one another. Nurses were more hesitant to admit and report errors; only $55 \%$ of physicians and $44 \%$ of nurses endorsed this statement $\left(\chi^{2}=4.9, p=0.02\right)$. Moreover, nurses received lower scores on team work compared with doctors ( $N 45.7$ vs D 52.3, $p=0.01$ ). Doctors denied the effects of stress and fatigue on their performance ( $\mathrm{N} 46.7$ vs D 39.5, $p<0.01$ ), neglecting the workload.

Conclusions: The $S A Q$ is a useful tool for evaluating safety attitudes in Albanian hospitals. In light of the health workforce's poor recognition of stress, establishing patient safety programmes should be a priority among policymakers in Albania.

\section{BACKGROUND}

Patient safety is viewed as a crucial component of quality in healthcare service. ${ }^{1}$ Over the last decade, numerous definitions of patient
Strengths and limitations of this study

The Safety Attitudes Questionnaire (SAQ) was easily answered and consistently well explained. Second, the group administration fully supported the survey, and parallel studies showed an ongoing commitment to patient safety and maintaining a safety culture. Third, all of the respondents were anonymous. Although anonymity may have allowed the participants to feel more comfortable about completing the questionnaire, we cannot rule out the possibility that some potential participants hesitated to participate for fear of persecution or job harm.

- We are aware of several limitations of our study. The SAQ tool relies strongly on self-reported behaviour. The resulting information may be biased and not correctly reflect the actual situation. A positive-answering tendency cannot be excluded. Staff perceptions of communication can vary over time and can be influenced by dayto-day events within the hospital setting. The external validity of the study findings was limited by the study design and participants. Finally, we did not examine variations in perceptions among departments or across hospital settings.

safety have emerged in the literature. The Institute of Medicine ${ }^{2}$ described patient safety as the prevention of harm. However, the European agency Safety Improvement for Patients in Europe asserted that patient safety focuses on identifying, analysing and minimising patient risk. ${ }^{3}$

Several studies have noted patient safety issues in different contexts. For example, study results from the USA revealed that one-fifth of the people in a community in New York reported that either they or someone in their household had experienced a medical error ${ }^{4}$ (an adverse event is defined as an injury resulting from a medical intervention and not caused by an underlying medical condition).$^{5}$

European data, mostly from European Union (EU) Member States, show that medical errors and healthcare-related adverse 
events occur in $8-12 \%$ of hospitalisations. Infections associated with healthcare affect an estimated 1 in 20 hospital patients on average every year (an estimated 4.1 million patients). The UK National Audit Office estimates the cost of such infections at $£ 1$ billion/year. ${ }^{6}$

A recently released European Commission report titled Patient Safety in EU: 2014 elucidated an array of occurrences related to healthcare-associated infections that are directly responsible for 37000 deaths/year, contribute to a further 110000 deaths/year and cost hospitals more than $€ 5.4$ billion/year. ${ }^{7}$

In healthcare, a significant percentage of errors are attributed to communication breakdowns and a lack of effective teamwork. ${ }^{8}$ Furthermore, poor communication and ineffective teamwork are factors that contribute to the occurrence of patient safety incidents. ${ }^{8-11}$ Effective teamwork and communication are considered critical for ensuring high reliability and the safe delivery of care. Teamwork and communication techniques can improve quality and safety, decrease patient harm, promote cross-professional collaboration and the development of common goals, decrease workload issues, and improve staff and patient satisfaction. ${ }^{8}$ To this end, hospitals need to assess patient safety and promote teamwork principles to create safe hospital systems. ${ }^{5} 1213$

\section{THE TRANSITIONAL ALBANIAN HEALTH SYSTEM}

\section{The Albanian health system}

Following various reforms that began in 1995 and have gained pace in recent years, the Albanian Health Care System moved from a typical Semashko model to a Bismarck model. ${ }^{14}$ The decentralisation of primary care management, the complete privatisation of the pharmaceutical sector and dentistry and the founding of the Health Insurance Institute (HII) were the main milestones of these reforms. The health system is funded through a mix of general tax revenues, payroll tax revenues for the compulsory HII, voluntary prepayment for Voluntary Health Insurance (offered by HII), out-of-pocket payments made at the time of service use and various international donors. ${ }^{14}$

Healthcare in Albania remains mainly public/state provided and is only partly privately provided. It is divided into three levels: primary, secondary and tertiary healthcare services. Healthcare services cover the entire country and are directed by the Ministry of Health. ${ }^{15}$ The Ministry of Health has been rapidly changing from its traditional role as a 'health directorate' to a leadership role in health policy development and health strategy implementation. However, the Ministry of Health remains the major healthcare financing body, providing two-thirds of the total healthcare budget. The Ministry of Health is also a policymaker, decision maker and manager, and it leads human resources and training. ${ }^{14-16}$ There are 4577 physicians in Albania and 709 inhabitants per physician. ${ }^{17}$

\section{The Albanian hospital decentralisation process}

Albania is engaged in health reform initiatives that aim to introduce primary healthcare centred on family medicine to enhance the performance of the health system and to cope with a broader political agenda. ${ }^{18}$ There is also a focus on hospital decentralisation reforms as part of an overall institutional decentralisation process. ${ }^{19}$ Since the beginning of 2009, HII has had contracts with 39 hospitals in Albania: 1 tertiary hospital (in Tirana), 3 university hospitals (in Tirana), 11 regional hospitals and 24 district hospitals. The hospitals are financed according to a historical budget. In 2010, the contract between the HII and the hospitals also included elements related to quality and performance indicators; however, monitoring these indicators seems very difficult, if not impossible, because clinical protocols and medical hospital standards are not yet available. The hospitals in Albania are not yet entirely accredited. ${ }^{14}$ The healthcare sector remains substantially underfunded and understaffed, and it lacks adequate healthcare management. ${ }^{19}$

It is important to provide patients with much-needed safety because patient safety is an identifiable problem in hospitals. This approach would allow the provision of patient safety while avoiding blame games that divert attention away from the quality of care. Healthcare organisations often learn from errors in the use of local and national reporting systems. ${ }^{20}$ Patient safety programmes exist primarily in the EU. Outside the EU, they are in a latent position (as in Albania at present). There are no established programmes on error records. Formal hospital registers show that patient safety is an issue in this country. According to some findings, 'medical breaches' are directly connected to presumed medical corruption. ${ }^{21-23}$

There is a lack of research on patient safety in Albanian hospitals and primary care settings. Therefore, an instrument to measure healthcare professionals' attitudes about the safety climate in their hospitals would be helpful for understanding and identifying areas that need improvement and for evaluating improvements in interventions. The purpose of the present study was to establish the reliability and validity of the translated version of the Safety Attitudes Questionnaire (SAQ; Hospital Version) by evaluating its psychometric properties. Moreover, we aimed to determine whether there are differences among nurses and physicians regarding safety attitudes.

Previous research has assessed the psychometric properties of the SAQ across countries ${ }^{24}{ }^{25}$ and in different contexts and settings. The internal consistency and Cronbach's $\alpha$ values are acceptable, and the construct validity measured by confirmatory factor analysis (CFA) generally exhibits satisfactory model fit. ${ }^{24-26}$ However, no psychometric instruments have been developed to measure patient safety in Albanian hospital settings.

Our research hypotheses related to the study aim were as follows:

H1. The data from this study confirm the proposed sixfactor model of the original SAQ. 
H2. The SAQ shows good internal consistency.

H3. The individual items of the SAQ show high correlations within their respective factors.

H4. There are no differences among nurses and physicians in terms of perceived patient safety attitudes in selected hospital settings.

\section{METHODS}

\section{Setting}

This was a quantitative, cross-sectional study. The data were collected between May and June 2012 at four regional hospitals in Albania. Nurses and doctors answered the SAQ-A voluntarily and anonymously. Surveys that were blank or had unvarying responses (eg, all of the responses were 'neutral' or 'agree strongly') were excluded from this analysis because they did not provide any diagnostic information.

\section{Participants}

One-stage cluster sampling was used in this study. Four hospitals were randomly selected from a list of 11 regional hospitals to ensure geographic representativeness. In each of the hospitals selected, both nurses and doctors were included in the survey.

The rationale behind choosing only two occupational groups (nurses vs doctors) was to explicitly compare these two groups with the distinctions regarding safety behaviour reported in the academic healthcare literature ${ }^{27-30}$ Nurses and doctors in Albanian hospitals function in a manner similar to that of a team; hence, their attitudes affect patient service and quality. The surveys were administered during predetermined departmental and staff meetings.

\section{MEASUREMENTS}

\section{Safety Attitudes Questionnaire}

The instrument used for data collection was the SAQ short adapted 30 -item version. ${ }^{31}$ The instrument comprises two parts. The first part contains questions that address perceptions of patient safety (table 1). The second part collects data about the professional respondent, including position held, sex, main job and years of experience.

The instrument measures healthcare professionals' perceptions in six areas, the teamwork climate, the safety climate, job satisfaction, perceptions of management, stress recognition and working conditions, with a response scale ranging from 1 (disagree strongly) to 5 (agree strongly). We chose the SAQ as an evaluation tool because of the strong correlation shown by previous studies between favourable SAQ scores and positive patient outcomes. ${ }^{31}$ Another reason was the proven validity and reliability of the SAQ in the countries in which it has been tested, including the USA, the UK, Turkey and Norway. ${ }^{24-26}$

There are other tools for evaluating the patient safety culture or the patient safety climate, such as Patient Safety Culture in Health care Organizations, ${ }^{32}$ the Manchester Patient Safety Assessment Framework ${ }^{33}$ and the Patient Safety Behavioural Intent (PSBI). ${ }^{34}$ These tools have been used in practice to highlight their potential strengths and weaknesses, as outlined in published research reports. However, the SAQ is one of the most commonly used and rigorously validated tools for measuring the safety climate in healthcare. A distinguishing feature of the SAQ is that higher scores on this survey have been associated with positive patient and staff outcome data. This feature contrasts with other tools that are less likely to have a direct association with patient outcomes. $^{35}$

\section{Safety culture versus safety climate: definition of terms}

Safety culture has a broad definition. It has been defined as a worldwide issue that incorporates the values, assumptions and drivers that guide an organisation. Alternately, the safety climate may involve a narrower scope by addressing the way employees perceive certain aspects of the organisational culture.

Measuring the safety climate is important because the culture of an organisation and the attitudes of teams have been found to influence patient safety outcomes, and measures of the safety climate can be used to monitor change over time. ${ }^{30} 35$

Some studies suggest that it is easier to measure the safety climate because culture is very broad, whereas the climate focuses on staff members' current perceptions of safety in relation to management support, supervision, risk taking, safety policies and practices, trust and openness. The safety climate is also thought to be more likely than culture to show change following interventions. ${ }^{36}$ Consequently, we chose to examine the safety

Table 1 Comparison of the Safety Attitudes Questionnaire (SAQ) scores among nurses and physicians

\begin{tabular}{lllrr}
\hline Subscale & Physicians & Nurses & t & p Value \\
\hline Teamwork & M (SD) & M (SD) & -5.4 & 0.01 \\
Safety climate & $52.3(10.7)$ & $45.7(11.3)$ & -1.5 & 0.1 \\
Stress recognition & $38.7(11.1)$ & $36.8(10.3)$ & 6.4 & $<.01$ \\
Job satisfaction & $39.5(9.2)$ & $46.7(11.4)$ & -7.8 & -1.6 \\
Perception of management & $49.7(9.2)$ & $40.6(12.2)$ & -9.7 & 0.1 \\
Working conditions & $46.8(9.6)$ & $44.8(13.1)$ & $29.2(13.4$ & 0.01 \\
\hline
\end{tabular}


climate in our study as an easily researched and manageable concept.

\section{STATISTICAL ANALYSIS}

The data analyses were conducted using SPSS V.16 (SPSS Inc, Chicago, Illinois, USA). CFA was conducted by structural equation modelling using AMOS V.5.0 software to test the extent to which each SAQ-A dimension was explained by the items and the extent to which safety attitude was explained by the six dimensions. Relative $\chi^{2}<5.0$, a comparative fit index (CFI) value of $\geq 0.95$, a root mean square error of approximation (RMSEA) value of $<0.08$ and a standardised root mean square residual (SRMR) value of $<0.09$ were considered to demonstrate acceptable model fit. The internal consistency of the Albanian version of the SAQ was assessed using Cronbach's $\alpha$ coefficient. Two items were negatively worded and were reversed for the statistical analysis. An independent sample t test was used to compare the mean score of the SAQ subscales between physicians and nurses. The $\chi^{2}$ test was used to compare the proportions of the responses between physicians and nurses. Pearson's correlation coefficient was used to examine the relationship between the SAQ subscales. A $p$ value $\leq 0.05$ was considered statistically significant.

\section{ETHICAL ISSUES}

Approval by an ethical committee was not necessary because the study had no experimental design and did not involve patients. Moreover, we were informed that it was not mandatory to receive ethical approval from the hospital ethics committee. The study was conducted in line with the Helsinki Declaration using a survey. The participants were informed about the aims of the study. Responding to the questionnaire was voluntary and anonymous, and the participants were given the opportunity to opt-out without giving any explanation if they felt uncomfortable with the content of the questions.

\section{RESULTS}

\section{Albanian version of the $S A Q$}

The SAQ was translated from English to Albanian and back again by native speakers. To ensure that the version that was translated from English to Albanian was clear and used the correct words, a focus group comprising physicians, nurse experts and faculty members conducted a review. All of the components were reviewed for their conformity with Albanian culture. Linguistic validation of the translation was performed using the back-translation technique. The analytical results demonstrated that all six dimensions had good reliability (see tables 2 and 3). The experts' view determined the authenticity of the content on the basis of its relevance, appropriateness and importance to Albanian culture. A content validity ratio (CVR) and a content validity index (CVI) were calculated for each item. The mean
Table 2 Goodness-of-fit indices for the confirmatory factor analysis of the Safety Attitudes Questionnaire factors

Sample size 341

Standardized root mean square residual (SRMR) Root mean square error of approximation (RMSEA)

Comparative fit index (CFI)

0.075

0.044

0.97

CVR for the total scale was 0.96 , and the mean CVI was 0.82 , indicating satisfactory content validity. (The adapted version of the questionnaire is available from the authors on request).

\section{Survey responses}

A total of 341 valid questionnaires were returned from four hospitals for a response rate of $70 \%$. An analysis of the missing data showed that no item had more than $2 \%$ missing values (range $0-1.8 \%$ ). The majority of the participants $(63.6 \%)$ were females $(36.4 \%$ were males); $61.4 \%$ were physicians, and $38.6 \%$ were nurses (table 4 ).

\section{Internal construct validity}

The goodness-of-fit values used to evaluate the internal construct validity are displayed in table 3 . The SRMR value was 0.075 , the RMSEA value was 0.044 and the CFI value was 0.97 . These values indicate a good model fit approximation of the translated version of the SAQ.

The CFA indicated a good model fit for each dimension and for the entire safety construct: the GFI, TLI and CFI were $>0.90$, and the RMSEA was $<0.10$.

\section{Internal consistency}

The internal consistency of the six factors and the 30 items of the translated version of the SAQ had Cronbach's $\alpha$ values of 0.62 to 0.82 . Safety climate had the highest Cronbach's $\alpha$ values, and stress recognition had the lowest value (table 3 ).

The test of the hypothesised relationships among the factors and items showed that the correlation ranged from 0.02 to 0.89 and that five of the six factor correlations were significant. The teamwork climate was positively correlated with the safety climate $(\mathrm{r}=0.55, \mathrm{p}<0.01)$, job satisfaction $(\mathrm{r}=0.54, \quad \mathrm{p}<0.01)$, perceptions of

Table 3 Internal consistency for the six Safety Attitudes Questionnaire (SAQ) factors: Cronbach's $\alpha$

SAQ factors Cronbach's $\alpha$

Safety climate (7 items) 0.82

Teamwork climate (6 items)

Job satisfaction (5 items) 0.79

Stress recognition (4 items) 0.78

Perceptions of management (4 items)

0.62

Working conditions ( 4 items) 
Table 4 Characteristics of the survey respondents

\begin{tabular}{|c|c|c|}
\hline Variables & Physicians (n=209) & Nurses $(n=132)$ \\
\hline \multicolumn{3}{|c|}{ Gender, n (\%) } \\
\hline Female & $136(65.0)$ & $114(86.0)$ \\
\hline Male & $73(35.0)$ & $18(14.0)$ \\
\hline \multicolumn{3}{|c|}{ Age group (years) n (\%) } \\
\hline $21-30$ & $53(58.2)$ & $38(41.8)$ \\
\hline $31-40$ & $42(66.7)$ & 21 (33.3) \\
\hline $41-50$ & $55(59.1)$ & 38 (40.9) \\
\hline $51-60$ & 55 (69.6) & $24(30.4)$ \\
\hline$>60$ & $5(33.3)$ & $10(66.7)$ \\
\hline
\end{tabular}

management $(\mathrm{r}=0.68, \mathrm{p}<0.01)$ and working conditions $(\mathrm{r}=0.68, \mathrm{p}<0.01)$, whereas the stress recognition subscale was not significantly related to any subscales.

The intercorrelations among the factors are presented in table 5 .

\section{SAQ factors and item descriptions and overall positive responsiveness per scale}

The SAQ factor definitions and items, the missing answers, the mean (SD), and agreement (agree strongly) and disagreement (disagree strongly) responses are described in table 6 .

The percentage of hospital healthcare providers who reported having a positive attitude was $60.3 \%$ for the teamwork climate, $57.2 \%$ for the safety climate, $58.4 \%$ for job satisfaction, $37.4 \%$ for stress recognition, $59.3 \%$ for the perception of management and $49.5 \%$ for working conditions.

\section{Group comparisons: nurses' behaviours versus physicians' behaviours}

The results of the $t$ test for independent samples did not indicate any significant difference between the scores of physicians and the scores of nurses with regard to the safety climate $(\mathrm{t}=-1.5, \mathrm{p}=0.1)$ and the perception of management $(\mathrm{t}=-1.6, \mathrm{p}=0.1)$ subscales, showing the same perceptions of attitude. A significant difference was found between the scores of the physicians and nurses for the teamwork $(\mathrm{t}=-5.4, \mathrm{p}<0.01)$, stress recognition $(\mathrm{t}=6.4, \mathrm{p}<0.01)$, job satisfaction $(\mathrm{t}=-7.8, \mathrm{p}<0.01)$ and working conditions subscales $(\mathrm{t}=-9.7, \mathrm{p}<0.01)$.
For the statement, "When my workload becomes excessive, my performance is impaired", a lower proportion of physicians and nurses endorsed the 'agree' option; this result achieved statistical significance (39\% physicians vs $51 \%$ nurses; $\left.\chi^{2}=5.0, \mathrm{p}=0.02\right)$.

For the statement "I am provided with adequate, timely information about events in the hospital that might affect my work", $59 \%$ of the physicians responded positively compared with $34 \%$ of the nurses $\left(\chi^{2}=18.8, \mathrm{p}<0.01\right)$.

Regarding the item "The culture in this hospital makes it easy to learn from the errors of others", a high percentage of the nurses and physicians agreed with the statement $(80.2 \%$ of the nurses and $83 \%$ of the physicians; $\left.\chi^{2}=0.1, \mathrm{p}=0.6\right)$. The nurses and doctors also agreed with the statement, "In this hospital, it is difficult to discuss errors"; the nurses felt more intimidated by discussing errors $(55 \%$ of the physicians vs $44 \%$ of the nurses; $\left.\chi^{2}=4.9, \mathrm{p}=0.02\right)$.

\section{DISCUSSION}

Previous studies in the area of patient safety have investigated the safety climate in primary care in Albania. ${ }^{39}$ The aim of the present study was to investigate perceptions of the safety climate among nurses and doctors working in hospital settings to confirm a validated tool (SAQ). According to the results of this study, construct validity based on the CFA and goodness-of-fit indices including CFI, SRMR and RMSEA demonstrated a good model that fit very well. It is imperative that a model should be made more specific and tested a second time in case a hypothetical model fails to fit appropriately. ${ }^{40} 41$ According to good model fit indices, the Albanian version of the SAQ is a valid measure of the safety attitude in hospitals. This finding is also an indication of the internal construct validity of the SAQ. The data from this study confirm our first hypothesis regarding the proposed six-factor model of the original SAQ (H1: The data from this study confirm the proposed six-factor model of the original SAQ).

The internal consistency and internal structure of the Albanian translation of the SAQ were assessed, and the translation showed satisfactory psychometric properties. The mean CVR for the total scale was 0.96 and the mean

\begin{tabular}{|c|c|c|c|c|c|c|}
\hline Subscale & $\begin{array}{l}\text { Safety } \\
\text { climate }\end{array}$ & $\begin{array}{l}\text { Teamwork } \\
\text { climate }\end{array}$ & $\begin{array}{l}\text { Job } \\
\text { satisfaction }\end{array}$ & $\begin{array}{l}\text { Stress } \\
\text { recognition }\end{array}$ & $\begin{array}{l}\text { Perception of } \\
\text { management }\end{array}$ & $\begin{array}{l}\text { Working } \\
\text { conditions }\end{array}$ \\
\hline \multicolumn{7}{|l|}{ Safety climate } \\
\hline Teamwork climate & $0.55^{\star}$ & & & & & \\
\hline Job satisfaction & $0.46^{*}$ & $0.54^{*}$ & & & & \\
\hline Stress recognition & 0.25 & 0.08 & 0.02 & & & \\
\hline $\begin{array}{l}\text { Perceptions of } \\
\text { management }\end{array}$ & $0.54^{*}$ & $0.68^{*}$ & $0.47^{\star}$ & 0.15 & & \\
\hline Working conditions & $0.68^{*}$ & $0.71^{*}$ & $0.61^{*}$ & 0.25 & $0.79^{*}$ & \\
\hline
\end{tabular}




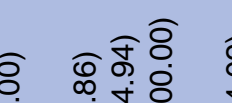

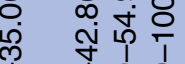

8 8ㅇำ

๑ @

$\infty \div$

하유

응ํㅇ

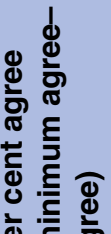

ㅇํㅇㅇำ

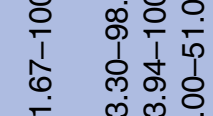

¿

ल्ర

あ

ติ

๖

ه तัर

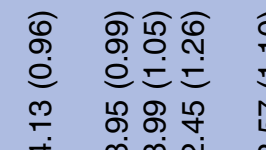

营

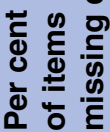
$\cos ^{2}$

$m-a n$

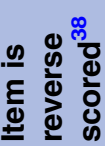

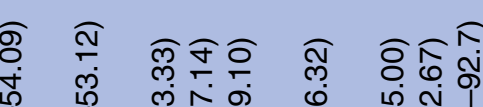

88

@ @

离

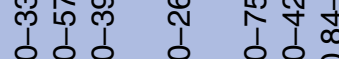

8.8 8 880

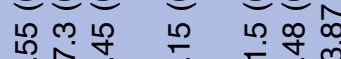

के

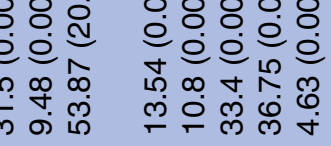

\section{ธิธ ธิธิ}

นุำ

กิ่

ले

ल्र过

ᄂᄋ 0 은

它它

क्ष

$=5=$

ㅇํㅇ 워

ले ले \begin{tabular}{llll}
\hline & 0 & 1 & 0 \\
1 & 1 & 1 & 1 \\
0 & 0 & $m$ & 0 \\
0 & 0 & 0 & 0
\end{tabular}

क ذं

m

N

अ तुष

¿ Е

ㅇำ

กิธู์ กิ

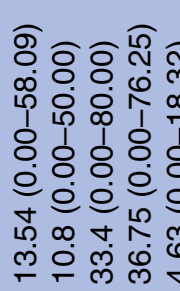

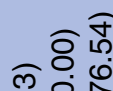

तิ่

$18 \stackrel{0}{\circ}$

은

के

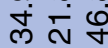

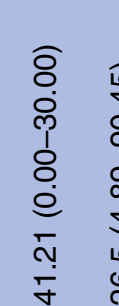

ฉิธ

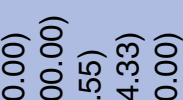

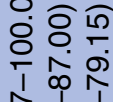

1)

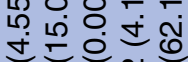

in $8 \stackrel{0}{1}$

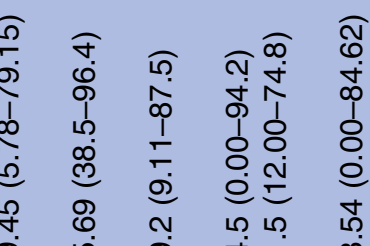

L $10-N 0$

당

0 L

ชै

लิ่ फ़्

ठิं ถึ

कि

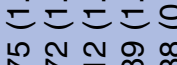

ᄃこ二

쇼

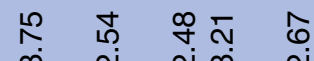

ले ले ले

लं लं

$$
\text { तल }
$$

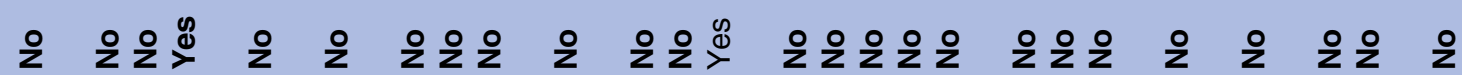

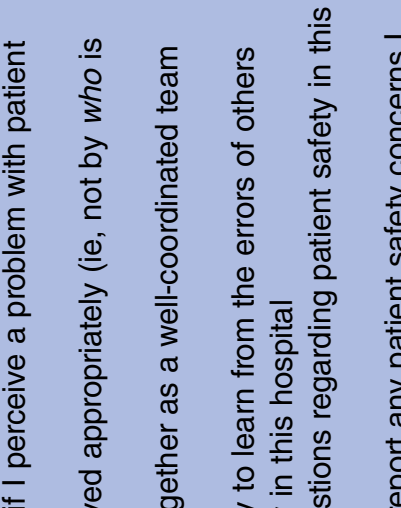

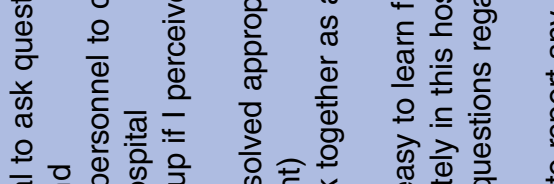

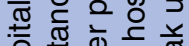

की

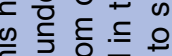

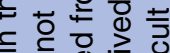

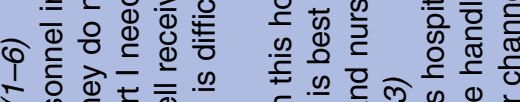

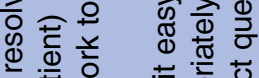

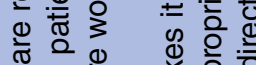

$\bar{\square} \stackrel{\infty}{5}$

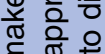

की 흔

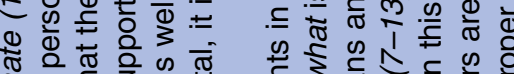

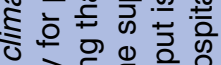

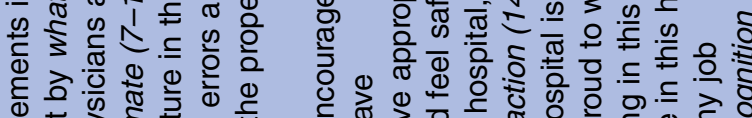

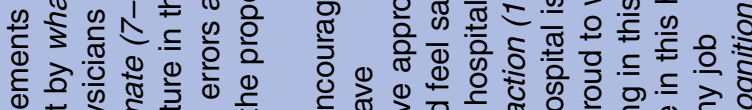

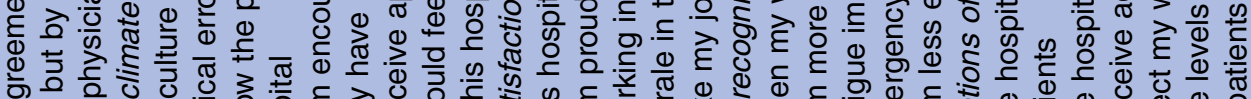

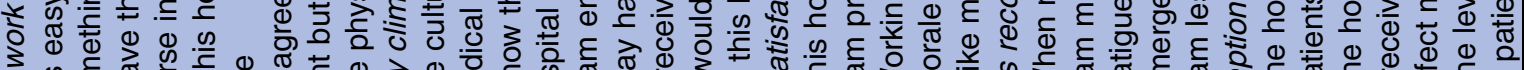

ह. ه্

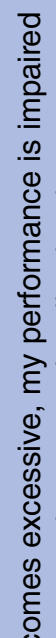

政 तิ సै

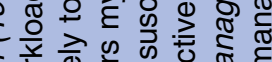

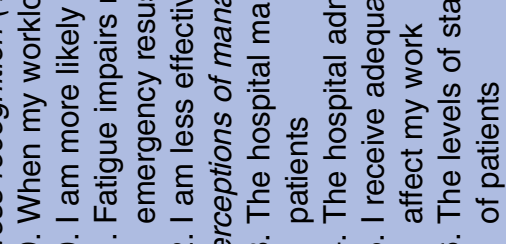
崩 


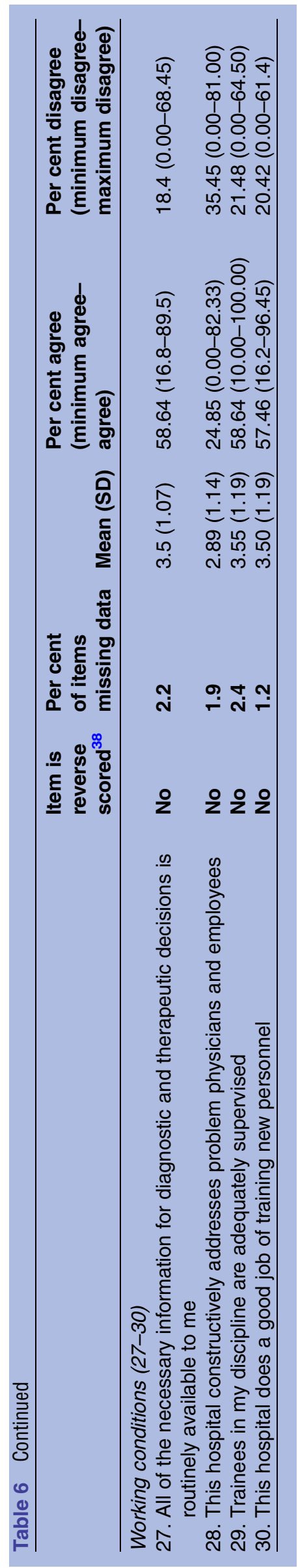

CVI was 0.82 , indicating satisfactory content validity. A good model fit was indicated by the construct validity, and its goodness-of-fit was used to determine the CFA. Based on the Cronbach's $\alpha$ values, the internal consistency of the six factors of the Albanian version of the SAQ showed values between 0.62 and 0.82 . Job satisfaction and the perception of management had $\alpha$ values of 0.62 and 0.64 , respectively, which are slightly below the recommended acceptable $\alpha$ value limit of 0.70 because of missing data that may have influenced the result. ${ }^{41}$ The study results showed good internal consistency, confirming our second hypothesis (H2: The SAQ shows good internal consistency). To apply the SAQ in Albania and ensure its reliability, the outcomes of this research should be considered in future evaluations. Cultural aspects may exist regarding the perception of management in the Albanian setting. For example, hospital directors are quasi-political appointees, and physicians may have little training in healthcare management ${ }^{16}$ and thus may lack the competency to properly evaluate overall management issues.

The study confirmed the third hypothesis based on the conclusion that all of the factors, with the exception of stress recognition, were interconnected (H3: Individual items of the SAQ show high correlations within their respective factors). According to the study results (see table 5), the teamwork climate was more positively correlated with the perceptions reported for the management and working conditions subscales. Stress recognition was not correlated with any of the subscales. These findings complement those of the psychometric testing for the original SAQ. In accordance with previous studies, stress recognition did not show a relationship with the perceptions of management, the teamwork climate, and job satisfaction, factors with moderate-to-high correlations. ${ }^{24}$ A significant difference in the perceived patient safety attitudes for the subscales of teamwork, safety climate, job satisfaction and working conditions was found between the nurses and physicians, with the nurses scoring lower mean values (see table 1). Overall, the nurses perceived lower job satisfaction, worse working conditions, a lower level of teamwork and poorer perceptions of management compared with doctors. Thus, our fourth hypothesis was not confirmed (H4: There is no difference among nurses and physicians in terms of perceived patient safety attitudes in selected hospital settings).

Other clinical areas have categorically shown broad distinctions between nurses and physicians. ${ }^{27} 28$ Two studies in the USA that used the SAQ showed that nurses and doctors differed in their perceptions of safety culture, ${ }^{29}{ }^{30}$ possibly because of the personal characteristics of the caregivers, such as their level of education, socioeconomic status and gender.

The traditional hierarchy of physicians has often discouraged nurses from speaking up to doctors. Nurses may be hesitant to confront physicians on issues of patient care because they might have less training in or 
experience with dealing with patients' medical conditions. ${ }^{30}$ In our study, the nurses consistently showed low mean scores for working conditions, safety climate and job satisfaction. Another study that examined nurses' job satisfaction showed that $41 \%$ of nurses were dissatisfied with their work in the USA; in England, $38.9 \%$ of nurses intended to abandon the profession. Generally, salary, professional growth and autonomy are some of the factors that influence the nursing professional's job satisfaction. ${ }^{42}$ National researchers in Albania have noted that nurses were less satisfied with their promotion opportunities and coworker satisfaction. ${ }^{43}$ WHO studies stress the limited formal opportunities to upgrade knowledge and skills through continuing professional development. ${ }^{44}$ From the study results, it is clear that the international benchmark standards were not met, ${ }^{24}$ as evidenced by the failure of the mean values in relation to the five safety dimensions.

\section{Managerial implications}

Measuring safety climate dimensions such as perceived teamwork climate, job satisfaction and the perception of management in hospitals can help to diagnose the underlying safety culture of an entire organisation or work unit. This study created a thorough image of nurses' and doctors' behaviour regarding issues such as teamwork, the safety climate, stress at work, job satisfaction and management support in the selected regional hospitals.

European integration could increase the mobilisation of human resources for health to other countries (eg, immediately after acceding to the EU in 2007, Romania reported more than 6000 requests for certificates recognising the Romanian diplomas of doctors, dentists, pharmacists and nurses for use elsewhere in the Union ${ }^{44}$ ).

In light of hospital decentralisation reforms and $\mathrm{EU}$ adherence, ${ }^{16}{ }^{19}$ this study serves as a starting point for initiating policy changes to address the issues identified above, such as improving job satisfaction, working conditions and the perceived inadequate information flow among nurses, and to implement interventions targeted to reduce the impact of these factors on the quality of hospital care.

The prevailing culture influences safety behaviours and outcomes for both healthcare workers and patients. This study has shown that the SAQ-A is a valid and easily administered instrument. As a first step, hospitals can use this tool to measure their employees' safety attitudes on a regular basis. Moreover, healthcare managers can use the resulting data to design effective safety management systems and possible interventions, such as promoting teamwork or stress recognition among doctors and nurses.

The results of this study can serve as baseline information for researchers with a variety of research interests, especially those related to patient safety and human resources for health.

From a cultural perspective, the results serve as a basis for comparison with other countries or systems that have their own particularities but share important common features with Albania (in terms of health services organisation, financing and regulation and similar evolutions of these systems).

\section{Promoting patient empowerment and a positive safety culture}

Over the past two decades, many policy documents, national priorities and guidelines across Europe, North America, Australia and sections of the Asian continent have been developed with messages about developing a positive safety culture with regard to healthcare. ${ }^{45} 46$ These types of initiatives are quite scarce and latent in Albania. Below, we present a contextualised framework (figure 1) that takes into account the Albanian Health Care System when considering how to promote a safety culture in an underfinanced healthcare system. The authors hope to broaden this perspective to similar health systems in Eastern European countries. Our main goal was to develop and test a framework for making the concept of safety culture meaningful and accessible to policymakers, healthcare managers and front-line staff, thus helping to facilitate a debate about ways to improve the safety culture in Albanian healthcare settings. We used a comprehensive review of the literature and national policy documents to identify the key dimensions of safety culture in healthcare settings.

The voices of patients and professionals are largely absent in the field of patient safety in Albania. For example, patients are considered to be passive and to maintain a troublesome apathy towards involvement in the healthcare decision-making process ${ }^{47}$ with regard to the country's informal payment phenomenon, which has deleterious effects on the Albanian health system. More active involvement of patients will help to diffuse and scale up patient safety programmes that have been successfully implemented in Western Europe and outside EU-developed countries.

\section{Further research needed}

The topic of patient safety is becoming increasingly prominent in political agendas. ${ }^{48}$ Reduced revenues and increasing expenditures in times of financial crisis are likely to increase pressure on health systems to further

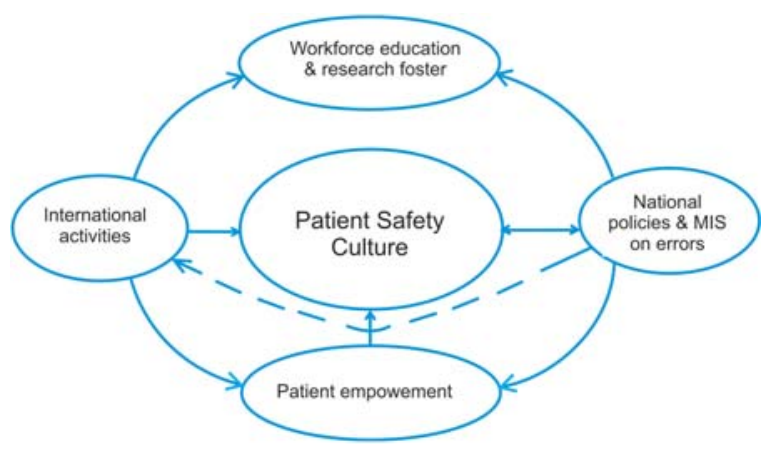

Figure 1 Gabrani and Petela, promoting safety culture frame in Albanian healthcare settings. 
contain costs, thus affecting service quality and patient safety. ${ }^{49}$ According to one recent cost-effectiveness study on patient safety, interventions show that specific actions related to patient safety can be cost-effective. ${ }^{50}$

To cope with the EU policy measures and reduce the costs of unsafe care and to develop cost-effective patient safety programmes in Albania, further research is needed. Furthermore, work is needed to better identify and design solutions that fit into existing institutional and organisational frameworks. At the hospital level, there is a need to understand the differences in attitudes among nurses and doctors and to better understand their low mean values on the scales compared with international benchmarks, ${ }^{24}$ especially in terms of the stress and fatigue recognition scale.

\section{CONCLUSIONS}

It is apparent that the psychometric aspects and the translation of the SAQ indicate good construct validity. Nonetheless, the reliability analysis suggested that some items need further refinement to establish sound internal consistency. The SAQ is clearly a useful tool for evaluating safety attitudes in Albanian hospital settings, and it confirmed our main hypothesis, H1. The data from this study also confirmed the proposed six-factor model of the original SAQ H2. The SAQ showed good internal consistency, H3. Individual items of the SAQ showed high correlations within their respective factors.

As previous research suggests, the SAQ has potential as a useful tool for evaluating safety attitudes. Regarding our study, there is room for improvement, especially in terms of generalising the findings to larger samples and conducting additional exploratory analyses to identify a better factor model. Moreover, the researchers are committed to adapting a new version of the tool by combining it with in-depth interviews to learn more about the differences in nurses' and doctors' safety attitudes.

Acknowledgements The authors would like to thank the students of the Faculty of Public Health for their outstanding assistance with data collection. The authors also thank all of the hospital healthcare workers who were part of this research study. Special thanks for your very helpful comments about the safety culture, stress and error reporting in the healthcare environment. Special thanks also for the auspicious guidance of Wendy Knibb, professor at the Schools of Health and Social Care, Faculty of Health and Medical Sciences, University of Surrey, UK, and to Gilles Dussault, professor at the Institute of Hygiene and Tropical Medicine (IHMT), Portugal. They thank American Journal Experts (AJE) for the English language editing.

Contributors AG designed the study. AH and JCG refined the writing strategy and the analysis elaboration. AS and JCG performed the data analysis, and JCG wrote the manuscript. JCG, AH and AS designed (adapted) the questionnaire and led the data collection process. All of the authors assisted with the data collection and the manuscript preparation and modified and approved the final manuscript. $A G$ and $A H$ share the primary contribution to the article.

Funding This research received no specific grant from any funding agency in the public, commercial or not-for-profit sectors.

Competing interests None declared.

Provenance and peer review Not commissioned; externally peer reviewed.
Data sharing statement No additional data are available.

Open Access This is an Open Access article distributed in accordance with the Creative Commons Attribution Non Commercial (CC BY-NC 4.0) license, which permits others to distribute, remix, adapt, build upon this work noncommercially, and license their derivative works on different terms, provided the original work is properly cited and the use is non-commercial. See: http:// creativecommons.org/licenses/by-nc/4.0/

\section{REFERENCES}

1. Institute of Medicine. Crossing the quality chasm: a new health system for the 21st century. Washington, DC: National Academy Press, 2001.

2. Institute of Medicine. Patient safety: achieving a new standard of care. Washington, DC: National Academy Press, 2003.

3. European Agency Safety Improvement for Patients in Europe (SIMPATIE). A Patient Safety Vocabulary Safety Improvement for Patients in Europe. http://www.hope.be/03activities/docsactivities/ SIMPATIE_Patient_safety_vocabulary_Professionals.pdf

4. Adams RE, Boscarino JA. A community survey of medical errors in New York. Int J Qual Health Care 2004;16:353-62.

5. Kohn L, Corrigan J, Donaldson M. To err is human: building a safer health system Institute of Medicine Report. Washington, DC: National Academy Press, 1999.

6. WHO. Patient Safety, Data and statistics. 2014. http://www.euro.who int/en/health-topics/Health-systems/patient-safety/data-and-statistics

7. European Commission. Info graph "Patient Safety in the EU: 2014". http://ec.europa.eu/health/patient_safety/docs/ps2014_infograph_en. pdf

8. Teamwork and Communication Working Group. Improving patient safety with effective teamwork and communication: literature review needs assessment, evaluation of training tools and expert consultations. Edmonton (AB): Canadian Patient Safety Institute, 2011.

9. Gawande AA, Zinner MJ, Studdert DM, et al. Analysis of errors reported by surgeons at three teaching hospitals. Surgery 2003;133:61421.

10. Sutcliffe KM, Lewton E, Rosenthal MM. Communication failures: an insidious contributor to medical mishaps. Acad Med 2004;79:186-94.

11. Risser DT, Rice MM, Salisbury ML, et al. The potential for improved teamwork to reduce medical errors in the emergency department. The Med Teams Research Consortium. Ann Emerg Med 1999;34:373-83.

12. Singer SJ, Vogus TJ. Reducing hospital errors: interventions that build safety culture. Annu Rev Public Health 2013;34:373-96.

13. Pronovost PJ, Weast B, Holzmueller CG, et al. Evaluation of the culture of safety: survey of clinicians and managers in an academic medical center. Qual Saf Health Care 2003;12:405-10.

14. Marku M. Preliminary analysis on Albanian Health System financing and corruption. Technical paper. Council of Europe, July 2010.

15. Albanian Ministry of Health. http://www.moh.gov.al/index.php/ organizimi-i-sistemit-shendetesor

16. Nuri B. In: Tragakes E. ed. Heath care systems in transition. Copenhagen, Albania: European Observatory on Health Care Systems, 2002:4. http://www.euro.who.int/_data/assets/pdf_file/ 0009/96426/E80089.pdf

17. Institute of Statistics (INSTAT), Institute of Public Health (ISHP), ICF Macro. Albanian Demographic and Health Survey 2008-09. Tirana, Albania. http://www.instat.gov.al/graphics/doc/downloads/ADHS/ ADHS_en.pdf

18. Atun RA, Ibragimov A, Ross $\mathrm{G}$, et al. Review of experience of family medicine in Europe and Central Asia: executive summary (in five volumes), vol. I. The World Bank Report No. 32354-ECA. Human Development Sector Unit, Europe and Central Asia Region. Washington, DC: The World Bank, May 2005.

19. Commission staff working document. Albania 2014 progress report Enlargement Strategy and Main Challenges 2014-2015. COM(2014) 700 final of 8.10.2014. http://ec.europa.eu/enlargement/pdf/key_ documents/2014/20141008-albania-progress-report en.pdf

20. European Commission. Patient Safety and Quality of Care Special Euro barometer report 411. June 2014. http://ec.europa.eu/health/ patient safety/docs/ebs 411 en.pdf

21. Cipi B. Medical malpractice problems and their influence in Albanian Health Care System. Revista Romana de Bioetica, [S.I.], v. 4, n. 2, feb. 2007. http://www.bioetica.ro/index.php/arhiva-bioetica/article/ view/420/600

22. Sida 2008, Sida Country Report 2007 Albania Art. no.: SIDA44891en. http://www.sida.se/publications 
23. Bir A, Eggleston K. Physician dual practice: access enhancement or demand inducement. Working Paper, Medford, MA: Tufts University, Department of Economics, 2003.

24. Sexton JB, Helmreich RL, Neilands TB, et al. The safety attitudes questionnaire: psychometric properties, benchmarking data, and emerging research. BMC Health Serv Res 2006;6:1-10.

25. Kaya S, Barsbay S, Karabulut E. The Turkish version of the safety attitudes questionnaire: psychometric properties and baseline data Qual Saf Health Care 2010;19:572-7.

26. Deilkås ET, Hofoss D. Psychometric properties of the Norwegian version of the safety attitudes questionnaire $(S A Q)$, generic version (Short Form 2006). BMC Health Serv Res 2008;8:1-10.

27. Thomas E, Sexton J, Helmreich R. Discrepant attitudes about teamwork among critical care nurses and physicians. Crit Care Med 2003;31:956-9.

28. Wiles R. Teamwork in primary care: the views and experiences of nurses, midwives and health visitors. $J$ Adv Nurs 1994;20:324-30.

29. Rosen AK, Gaba DM, Meterko M, et al. Recruitment of hospitals for a safety climate study: facilitators and barriers. Jt Comm J Qual Patient Saf 2008;34:275-84.

30. van Noord I, de Bruijne MC, Twisk JW. The relationship between patient safety culture and the implementation of organizational patient safety defences at emergency departments. Int J Qual Health Care 2010;22:162-9.

31. Sexton JB, Thomas EJ. The Safety Climate Survey: psychometric and benchmarking properties. Technical Report 03-03. The University of Texas. Center of Excellence for Patient Safety Research and Practice (AHRQ grant \# 1PO1HS1154401 and U18HS1116401).

32. Singer S, Meterko M, Baker L, et al. Workforce perceptions of hospital safety culture: development and validation of the patient safety climate in healthcare organizations survey. Health Serv Res 2007;42:1999-2021.

33. The Manchester Patient Safety Framework (MaPSaF) research team, University of Manchester. Manchester Patient Safety Assessment Framework. http://www.nrls.npsa.nhs.uk/EasySiteWeb/ getresource. axd? AssetID=60005\&type=full\&servicetype=Attachment

34. Wakefield JG, McLaws ML, Whitby M, et al. Patient safety culture: factors that influence clinician involvement in patient safety behaviors. Qual Saf Health Care 2010;19:585-91.

35. Pronovost $P$, Sexton B. Assessing safety culture: guidelines and recommendations. Qual Saf Health Care 2005;14:231-3.
36. The Health Foundation. Research scan: measuring safety culture. February 2011. http://patientsafety.health.org.uk/sites/default/files/ resources/measuring_safety_culture.pdf

37. Flin R, Burns $\mathrm{C}$, Mearns $\mathrm{K}$, et al. Measuring safety climate in health care. Qual Saf Health Care 2006;15:109-15.

38. Sexton JB, Thomas EJ, Grillo SP. The Safety Attitudes Questionnaire: guidelines for administration, Volume 2/03. Texas: University of Texas, 2003:12.

39. Gabrani A, Petela E, Gabrani J. Patient safety in Albania. European Health Management Association conference; 2012.

40. Polit DF, Beck CT. Nursing research. Generating and assessing evidence for nursing practice. 8th edn. Crawfordsville: Lippincot Williams \& Wilkins, 2008

41. Nunnaly J, Bernstein I. Psychometric theory. 3rd edn. New York: McGraw Hill, 1994.

42. Needleman J, Buerhaus $P$, Mattke S, et al. Nurse-staffing levels and the quality of care in hospitals. N Engl J Med 2002;346:1715-22.

43. Gabrani (Cyco) J, Gabrani A, Petrela E, et al. Organizational commitment and job satisfaction among nurses in public hospitals in Albania. The 1st International Conference on Research and Education-Challenges Toward the Future (ICRAE2013), 24-25 May 2013, University of Shkodra. Luigj Gurakuq

44. World Health Organization. Attracting and retaining health workers in the Member States of the South-eastern Europe Health Network. 2011.

45. Healthcare Commission. Investigation into outbreaks of Clostridium difficile at Stoke Mandeville Buckinghamshire Hospitals NHS Trust. London: Healthcare Commission, 2006.

46. Department of Health. High quality care for all. London: Stationary Office, 2008.

47. Gabrani A, Gabrani (Cyco) J, Petrela E, et al. Health System Responsiveness in Hospitals; approach on building the will in Albania. European Health Management Association Conference; 2013.

48. The Tallinn Charter. Health systems for health and wealth, draft 13 June 2008. Copenhagen: WHO Regional Office for Europe, 2008.

49. EUROSTAT 2009 figures. http://epp.eurostat.ec.europa.eu/portal/ page/portal/eurostat/home/

50. Vilamoska A, Conklin A. Improving patient safety: addressing patient harm arising from medical error, Policy Insight, 2009, 3(2), RAND Corporation. http://www.rand.org/pubs/corporate_pubs/ CP521-2009-04/ 